\title{
Relação entre a divulgação de informações contábeis nos padrões especificados pelas normas vigentes e as características organizacionais das fundações privadas brasileiras
}

\section{Relationship between accounting informations reported under the current norms and the organizational characteristics of Brazilian private foundations}

\author{
Cássia Vanessa Olak Alves Cruz ${ }^{1}$, Luiz Alberto da Silva Reis ${ }^{2}$, \\ Layra Duarte Estecanela ${ }^{2}$, Miriam Akemi Tanita de Souza ${ }^{2}$
}

\begin{abstract}
Resumo
O objetivo desta pesquisa é verificar a relação entre a divulgação de informações contábeis nos padrões especificados pelas normas vigentes e as características organizacionais das fundações privadas brasileiras. Para alcance desta finalidade, realizou-se uma pesquisa documental, com delineamento metodológico descritivo e explicativo, sendo analisados os relatórios contábeis, relativos aos exercícios findos em 2015, das fundações privadas formalmente constituídas no cenário brasileiro. A população de estudo abrangeu 8.123 entidades, sendo investigadas 384 instituições que compuseram a amostra probabilística. A análise dos dados se deu através da utilização de um checklist composto por 41 itens que englobam reconhecimento, demonstrações contábeis obrigatórias e conteúdo das notas explicativas. Verificou-se que o nível de conformidade geral das referidas fundações com a ITG 2002 (R1) foi de 64,53\%, concluindo-se, então, que as entidades não estão atendendo a todos os requisitos exigidos pelas normas contábeis vigentes. Foi correlacionado, através da técnica de correlação de Pearson e regressão linear múltipla, o nível de conformidade com as características organizacionais de porte, tempo de constituição, auditoria externa e subvenções governamentais. Conclui-se que os fatores porte e presença de auditoria externa têm relação positiva e significativa com o nível de conformidade das demonstrações contábeis, enquanto o tempo de constituição apresentou relação negativa.
\end{abstract}

Palavras-chave: Terceiro Setor. Nível de conformidade. Normas contábeis. Fatores explicativos. Características organizacionais.

\footnotetext{
${ }^{1}$ Doutorado em Ciências Contábeis pela Faculdade de Economia, Administração, Contabilidade e Atuária da Universidade de São Paulo (FEA-USP), São Paulo, São Paulo, Brasil. Professora Associada da Universidade Estadual de Londrina (UEL), Londrina, Paraná, Brasil. E-mail: cassiavanessa@uel.br

${ }^{2}$ Graduação em Ciências Contábeis pela Universidade Estadual de Londrina, Londrina, Paraná, Brasil.
} 


\begin{abstract}
This study investigates the relationship between accounting informations reported under the current accounting standards and the organizational characteristics of Brazilian private foundations. The investigation was performed on accounting statements reported by active and formally constituted private foundations on the 2015 accounting year, following the descriptive and explanatory design. The analysis covered a sample of 384 organizations, randomly sampled from a population encompassing 8.123 entities. To collect the data, we used a checklist of 41 items that include recognition, accounting statements and the content of the explanatory notes. The average level of compliance of the sampled institutions to the norms in the ITG 2002 (R1) was $64.53 \%$, showing that a large amount of the institutions in the scope of this investigation did not meet all the requirements. The level of compliance with the organizational characteristics of size, constitution time, external audit and government subsidies were correlated through Pearson's technique and multiple linear regression. It was concluded that, size and presence of external audit had a positive and significant correlation with the level of compliance of the financial statements while time of constitution had a negative correlation.
\end{abstract}

Keywords: Third Sector. Level of compliance. Accounting norms. Explanatory factors. Organizational characteristics.

\section{Introdução}

O Terceiro Setor (TS), também denominado de setor sem fins lucrativos (nonprofit sector), é constituído por instituições de origem privada, que não distribuem o lucro aos dirigentes, investidores ou empregados, que se dedicam à realização de objetivos sociais ou de interesse público, ainda que não sejam integrantes do Estado. Portanto, o TS é aquele que não é privado e nem público, no sentido convencional dessas expressões (FRANÇA, 2015).

As entidades do Terceiro Setor surgem como sustentáculo do poder público, uma vez que elas se caracterizam como complemento da administração pública. Fischer (2002) constata que o Estado brasileiro, em seu contexto histórico, em nenhum momento caracterizou-se em sua plenitude por um aparato de políticas sociais que garantiam aos cidadãos o suporte às necessidades básicas para a manutenção da vida social.

Nessa perspectiva, o Terceiro Setor passou a ter função substancial no apoio ao Estado no Brasil quanto às políticas públicas na área social. Esta realidade proporcionou um crescimento significativo deste segmento.

Devido à relevância dessas organizações do Terceiro Setor que exercem funções de interesse público ou coletivo na sociedade, espera-se que os seus relatórios contábeis sejam elaborados em conformidade com as Normas Brasileiras de Contabilidade. Esse processo proporciona maior credibilidade na prestação de contas das instituições, contribuindo ainda com a transparência das suas informações, o que pode ser um diferencial em relação às decisões de contribuições para essas entidades do TS.

Nos últimos anos, a contabilidade brasileira iniciou o processo de internacionalização das normas contábeis com a criação do Comitê de Pronunciamentos Contábeis (CPC) (CONSELHO FEDERAL DE CONTABILIDADE, 2005). Esse processo, como consequência, influenciou a contabilidade das entidades pertencentes ao Terceiro Setor.

Nesse sentido, França (2015, p. 31) destaca que:

[...] para a regulação contábil específica no Brasil para as entidades sem finalidade de lucro, o Conselho Federal de Contabilidade deu o passo definitivo, desta vez já dentro do processo de convergência aos padrões internacionais de contabilidade. Mais precisamente a partir de 21/9/2012, o Conselho Federal de Contabilidade, visando consolidar e integrar as resoluções e normas que tratavam 
das entidades de interesse social, aprovou a Interpretação Técnica ITG 2002 - Entidades Sem Finalidade de Lucros, cujo objetivo é estabelecer critérios e procedimentos contábeis específicos para entidades do Terceiro Setor (fundações e associações), no âmbito das normas internacionais de contabilidade.

"Por muitos motivos, as entidades sem fins lucrativos no Brasil não cultivam a transparência" (OLAK; NASCIMENTO, 2008, p. 23). A contabilidade das organizações do Terceiro Setor no cenário nacional apresenta um baixo índice de divulgação dos relatórios contábeis para os usuários, soma-se a isso a pouca divulgação de informações sobre o desempenho e atividades dessas instituições, diferentemente de países desenvolvidos (CRUZ, 2010).

Ramos e Klann (2015) identificaram que o índice de qualidade da informação divulgada pelas entidades do Terceiro Setor é inferior ao se comparar com o Segundo Setor. Verificaram, também, que características organizacionais como o tamanho e o tempo de constituição influenciam diretamente na qualidade da divulgação contábil das organizações analisadas. Porém, a coleta de dados das demonstrações contábeis examinadas no referido estudo foi feita através do Cadastro Nacional de Entidades Qualificadas pelo Ministério da Justiça (CNEs/MJ), que possuía informações padronizadas, ou seja, o sistema dispunha de um plano de contas e estruturas de demonstrativos padrões (BRASIL, 2007). Assim, é possível que os dados não evidenciem uma representação real e fidedigna dos relatórios contábeis que essas instituições praticam e divulgam.

Tendo em vista que a adoção das normas brasileiras de contabilidade é obrigatória e que as fundações de inciativa privada compõem o TS, a problemática de pesquisa a ser respondida pode ser assim expressa: "qual a relação entre a divulgação de informações contábeis nos padrões especificados pelas normas vigentes e as características organizacionais das fundações privadas brasileiras?".

Neste sentido, este trabalho tem por objetivo geral verificar a relação entre a divulgação de informações contábeis nos padrões especificados pelas normas vigentes e as características organizacionais das fundações privadas brasileiras.

A importância desta análise pauta-se em verificar se há associação entre o nível de evidenciação contábil e as características das entidades sem fins lucrativos, dando continuidade a estudos anteriores (PACHECO; MACAGNAN; SEIBERT, 2016; RAMOS; KLANN, 2015, LIMA; PEREIRA, 2011) que investigaram como características das organizações sem fins lucrativos influenciam na qualidade da divulgação de informações dessas instituições, no entanto, esta pesquisa utilizará os relatórios contábeis publicados diretamente pelas entidades estudadas, além de focar nas fundações privadas localizadas no Brasil.

A relevância deste estudo ainda pode ser percebida pela necessidade de investigações que esclareçam a baixa divulgação de informações contábeis no contexto do Terceiro Setor brasileiro. Ademais, este artigo contribui para a linha de pesquisas que analisam a importância da transparência das organizações do TS.

\section{Referencial Teórico}

\section{Transparência e evidenciação contábil das entidades do Terceiro Setor}

É crescente a participação e representatividade do Terceiro Setor no cenário brasileiro. De acordo com o Instituto Brasileiro de Geografia e Estatística (IBGE, 2010), o crescimento da quantidade de entidades no período compreendido entre 1996 e 2002 chegou a $136 \%$; e de 2002 a 2010 , a $12 \%$, atingindo 556 mil organizações sem fins lucrativos no Brasil em 2010, movimentando 1,5\% do Produto Interno Bruto (PIB). Tais fatos revelam maior relevância econômica e social do setor.

Pode-se observar, portanto, que a própria sociedade, através da organização dessas entidades, tem buscado suprir as necessidades sociais e melhorar as condições de qualidade de vida, complementando a ação do Estado (SILVEIRA; BORBA, 2010). 
As principais fontes de recursos financeiros e materiais das entidades do Terceiro Setor são oriundos de doações, contribuições, subvenções. Algumas delas podem também angariar recursos a partir de taxas cobradas da comunidade, sócios e associados por prestação de serviços. Portanto, é de fundamental importância que tais instituições demonstrem as aplicações de recursos para aqueles que financiam suas atividades, sejam órgãos governamentais ou a sociedade em geral, e assim evidenciem que estão cumprindo sua missão (CARNEIRO; OLIVEIRA; TORRES, 2011).

Uma relação transparente é essencial para a captação de recursos, pois ninguém destinaria, racionalmente, um valor de seu patrimônio a uma entidade que não fornece evidências de que a aplicação dos bens está sendo feita de forma apropriada. A partir do instante em que recebem recursos oriundos da sociedade, essas organizações têm como contrapartida o dever da gestão adequada desses recursos. Deste modo, é essencial a apresentação da prestação de contas, comumente chamada de accountability.

Para Assis, Mello e Slomski (2006), a accountability surge, por conseguinte, da necessidade dos gestores das entidades sem fins lucrativos de efetuar a prestação de contas dos resultados obtidos, decorrentes dos recursos aplicados que foram arrecadados em forma de doações. Ainda, segundo os autores, a contabilidade, por meio de mecanismos de evidenciação pode auxiliar no processo de produção de informação aos diversos usuários, demonstrando os resultados alcançados pela gestão destas entidades.

No caso das fundações privadas, a prestação de contas, na maioria dos Estados brasileiros, é realizada através do Sistema de Cadastro e Prestação de Contas (SICAP), que é um sistema de prestação de contas de responsabilidade do Ministério Público (MP) Estadual e tem sua obrigatoriedade anual. A exigência de prestação de contas é determinada pela sanção de atos normativos dispostos pelo MP de cada Estado brasileiro. Ressalta-se, porém, que os dados informados no SICAP podem não possuir uma representação real e fidedigna das demonstrações contábeis de cada fundação, já que o sistema possui um plano de contas e estruturas de demonstrativos padronizados e não individuais, distorcendo a qualidade das informações.

Sendo assim, uma das principais formas que as organizações do Terceiro Setor podem demonstrar transparência e prestar contas à sociedade é por meio da divulgação das demonstrações contábeis. Dessa forma, as que elaborarem suas demonstrações em consonância às normas vigentes e com qualidade, adquirem credibilidade no setor, que é fundamental para a sustentabilidade dessas entidades, que operam com recursos provenientes de seus parceiros (ROSSI JUNIOR, 1998).

Uma forma utilizada para se tratar de transparência é o termo Disclosure, que:

[...] diz respeito à qualidade das informações de caráter financeiro e econômico, sobre as operações, recursos e obrigações de uma entidade, que sejam úteis aos usuários das demonstrações contábeis, entendidas como sendo aquelas que de alguma forma influenciem na tomada de decisões, envolvendo a entidade e o acompanhamento da evolução patrimonial, possibilitando o conhecimento das ações passadas e a realização de inferências em relação ao futuro (NIYAMA; GOMES, 1996, p. 65).

Deste modo, a divulgação de informações contábeis obrigatórias e voluntárias é entendida como disclosure, que ainda pode ser definido como a ampla disponibilidade de informações específicas da entidade para aqueles que estão de fora da organização (BUSHMAN; PIOTROSKI; SMITH, 2004, p. 211).

Esta pesquisa tem como foco o disclosure obrigatório e a definição da sua extensão se fundamentará na legislação contábil em vigor aplicada ao Terceiro Setor, apresentada na seção seguinte.

\section{Normas contábeis e o Terceiro Setor}

Seguindo a tendência da internacionalização das Normas Contábeis, foi promulgada a 
Interpretação Técnica Geral (ITG) 2002 (CONSELHO FEDERALDE CONTABILIDADE, 2012), que tem por objetivo estabelecer:

[...] critérios e procedimentos específicos de avaliação, de reconhecimento das transações e variações patrimoniais, de estruturação das demonstrações contábeis e as informações mínimas a serem divulgadas em notas explicativas de entidade sem finalidade de lucros (CONSELHO FEDERAL DE CONTABILIDADE, 2012).

A ITG 2002 trouxe mudanças significativas nos procedimentos contábeis aplicáveis ao Terceiro Setor, como de avaliação, reconhecimento, registros contábeis, estrutura das demonstrações entre outros quesitos (CONSELHO FEDERAL DE CONTABILIDADE, 2012). Em 2015, a ITG 2002 sofreu sua primeira alteração, passando a ser nominada de ITG 2002 (R1) (CONSELHO FEDERAL DE CONTABILIDADE, 2012).

Frente a isso, a contabilidade do TS deve cumprir o conteúdo da ITG 2002 (R1)(CONSELHO FEDERAL DE CONTABILIDADE, 2015) e, nos aspectos não abordados pela mencionada Interpretação, deve observar "[...] a NBC TG 1000 - Contabilidade para Pequenas e Médias Empresas ou as normas completas (IFRS completas) [...]" (CONSELHO FEDERALDE CONTABILIDADE, 2015, item 4).

Porém, as normas de contabilidade, por si só, podem não determinar exclusivamente a qualidade da elaboração das demonstrações financeiras. Isto não quer dizer que as normas não sejam importantes, mas que há muitos fatores que determinam a qualidade dos relatórios contábeis, sendo as normas contábeis um deles (HOLTHAUSEN, 2009).

Apesar de obrigatórias e importantes para prover a credibilidade, pesquisas (RAMOS; KLANN, 2015; LIMA; PEREIRA, 2011) apontam que as normas da contabilidade não estão sendo cumpridas em sua totalidade por organizações do TS na elaboração dos seus demonstrativos contábeis.

\section{Relação entre o nível de conformidade} e as características organizacionais

Estudos que têm investigado relatórios contábeis e financeiros constataram existir relação positiva/negativa entre o nível de evidenciação informacional e características organizacionais em empresas privadas e organizações sem fins lucrativos em diferentes países. As características mais frequentes dessas instituições têm sido tamanho, presença de auditoria externa e sua reputação, idade (tempo de constituição) e recebimento de doações e subvenções.

O tamanho da empresa tem sido positivamente associado a níveis de divulgação em diversas pesquisas (UYAR; KILIC; BAYYURT, 2013; TRUSSEL; PARSONS 2007; JEGERS, 2008; MURCIA; SANTOS, 2012; HERCULANO; MOURA, 2015), sugerindo que organizações maiores adotam melhores práticas de disclosure em seus relatórios financeiros. Murcia e Santos (2009) descrevem que os custos aumentam à medida que se aumenta o volume de informação divulgada. Para empresas maiores, esses custos são facilmente absorvidos, já que possuem um maior nível de controle em seus processos, resultando em melhores informações contábeis. Além disso, como as instituições de maior porte estão mais expostas à sociedade do que as empresas de menor porte, elas tendem a divulgar mais informações (UYAR; KILIC; BAYYURT, 2013).

O tempo de existência da entidade, habitualmente conhecido como idade na literatura, pode ser apontado como característica de reputação. As organizações mais novas ainda necessitam ganhar espaço e visibilidade, o que outras mais antigas podem já ter solidificado, na visão dos stakeholders (CUNHA; MATIAS-PEREIRA, 2012). O tempo de constituição das organizações reflete a conotação de mais experiência, considerando que, com o passar do tempo, as instituições vão se aperfeiçoando, adotando melhores práticas e procedimentos que elevam o nível de gestão profissional, tornando os relatórios 
contábeis relevantes para a análise e tomada de decisão dos interessados nessas entidades.

A auditoria examina as demonstrações e registros contábeis com o objetivo de indicar aos diversos usuários que as demonstrações contábeis representam, fidedignamente, a situação financeira e patrimonial das entidades. Após a aplicação de um conjunto de procedimentos, o auditor emite um parecer ou relatório sobre a conformidade das demonstrações contábeis analisadas (CUNHA et al., 2010). A realização de auditoria proporciona que as demonstrações contábeis sejam mais confiáveis do que os relatórios de entidades que não são analisadas por auditores externos. Deste modo, estudos examinaram se existe relação da presença da auditoria independente e o nível de disclosure das demonstrações (UYAR; KILIC; BAYYURT, 2013; JEGERS, 2008; MURCIA; SANTOS, 2012).

Segundo o International Accounting Standards Board (2002, p. 462), as subvenções governamentais "[...] constituem em ajuda governamental, sob forma de transferência de recursos a uma empresa em retribuição ao cumprimento passado ou futuro de certas condições referentes às atividades operacionais da mesma". Trussel e Parsons (2008) demonstram que as entidades que recebem subvenções governamentais tendem a melhorar o controle e qualidade das divulgações das informações financeiras. Seguindo esta linha, Lima e Pereira (2011) verificaram que existe relação entre os índices de disclosure e as características corporativas "gratuidade" e "subvenção" nas Instituições de Ensino Superior Filantrópicas do Brasil.

Portanto, as características selecionadas para este estudo são: porte (ativo total), tempo de constituição (em anos), contratação de auditoria externa e obtenção de subvenções governamentais.

\section{Pesquisas assemelhadas}

O artigo de Ramos e Klann (2015) teve como objetivo verificar a relação entre a qualidade da informação contábil e as características organizacionais das entidades do Terceiro Setor. A população do estudo foi composta pelas entidades sem fins lucrativos com qualificação de OSCIPs (Organização da Sociedade Civil de Interesse Público) e UPF (Utilidade Pública Federal), com uma amostra de 392 entidades de um total de 18.553. A predominância da forma legal foi de associação. No que se refere à qualidade da informação contábil, constatou-se um baixo índice de qualidade da informação reportada, com a média de $32,4 \%$ de evidenciação contábil. Os resultados apontaram, ainda, que as características organizacionais de tamanho, tempo de constituição e qualificação como OSCIP possuem influência significativa e positiva sobre a qualidade da informação contábil das entidades analisadas.

Já a pesquisa de Lima e Pereira (2011) verificou se existe associação entre o nível de disclosure das Instituições de Ensino Superior Filantrópicas do Brasil - IESFB e algumas de suas características corporativas (tamanho, localização, alavancagem, gratuidade, benefícios fiscais e subvenção). O estudo analisou uma amostra de 146 entidades cadastradas no Conselho Nacional de Assistência Social (CNAS). As análises dos resultados dos testes apontaram associação significativa apenas entre os níveis de disclosure e as características corporativas "gratuidade" e "subvenção", não se observando associação entre esses níveis e as demais variáveis levantadas. Foi possível observar, ainda, que houve pouca preocupação dessas entidades com o disclosure voluntário. A maioria delas apresentou apenas disclosure obrigatório.

O estudo de Pacheco, Macagnan e Seibert (2016) analisou os fatores explicativos do nível de evidenciação de informações nas páginas eletrônicas de fundações educacionais e assistenciais sediadas no estado do Rio Grande do Sul. Com uma amostra composta por 48 fundações educacionais e assistenciais, foi realizada a análise de conteúdo e mensurado o nível de evidenciação de informações obrigatórias e voluntárias. Posteriormente, verificou-se que existe relação positiva entre o nível de doações recebidas, o 
número de pessoas beneficiadas e as organizações apoiadas ou beneficiadas, e o disclosure nas páginas eletrônicas publicadas na internet.

\section{Metodologia}

A população selecionada para esta pesquisa foi a classe das fundações privadas sediadas no Brasil, visto que, segundo o art. 66 do Código Civil (BRASIL, 2002) "Velará pelas fundações o Ministério Público do Estado onde situadas". Desta maneira, o Ministério Público de cada Estado detém em seu banco de dados a relação das fundações privadas oficialmente constituídas no país, que proporcionará a base para coleta de dados.

A fim de atender ao objetivo proposto neste estudo, foi realizada uma pesquisa documental que analisou os relatórios contábeis completos das entidades, sendo eles: Balanço Patrimonial, Demonstração do Resultado do Período, Demonstração das Mutações do Patrimônio Líquido, Demonstração dos Fluxos de Caixa e as Notas Explicativas. A pesquisa documental, segundo Martins e Theóphilo (2009), identificase pela utilização de documentos como fonte secundária de dados. $\mathrm{O}$ período analisado abrangeu as informações relativas ao exercício findo em 2015.

Este estudo tem uma abordagem qualiquantitativa, com ênfase na quantitativa, pois se utiliza de instrumentos estatísticos tanto na coleta das informações quanto no tratamento e análise delas.
Inicialmente, para obter os dados necessários para execução deste estudo, foi encaminhado aos Ministérios Públicos (MP) Estaduais um ofício solicitando uma relação das fundações privadas existentes e os dados necessários para contato com cada uma delas. Em resposta, os MP disponibilizaram listagens das fundações cadastradas, totalizando 8.123 entidades.

Posteriormente, com os dados de contatos obtidos, foi determinada, ao nível de confiança de 95\%, uma amostra probabilística de 384 instituições. Deste modo, realizou-se a coleta de dados das demonstrações contábeis, a princípio, nos sites das fundações. Após esta coleta, foram realizadas buscas em jornais e diários oficiais a fim de conseguir a base necessária de dados para dar continuidade à pesquisa.

Para o tratamento dos dados coletados, utilizou-se a análise descritiva, pois, segundo Colauto e Beuren (2014), pode ser empregada em estudos que buscam descrever características e esclarecer a relação entre variáveis. Neste caso, este artigo visa identificar o nível de conformidade às Normas Brasileiras de Contabilidade e relacionálas com as características organizacionais das fundações privadas. Este estudo caracteriza-se, ainda, como explicativo, uma vez que "[...] tem como preocupação central identificar os fatores que determinam ou que contribuem para a ocorrência dos fenômenos" (GIL, 2008, p. 42). O Quadro 1 apresenta as variáveis definidas para o estudo.

Quadro 1 - Descrição das variáveis utilizadas na estatística.

\begin{tabular}{|l|l|c|c|}
\hline \multicolumn{1}{|c|}{ Variáveis } & \multicolumn{1}{|c|}{ Proxy } & Sigla & Classificação \\
\hline Nível de conformidade & Índice (de 0 a 100\%) obtido através de check-list. & NC & Dependente \\
\hline Porte & Logaritmo natural do ativo total em 2015. & PORTE & Independente \\
\hline Tempo de constituição & $\begin{array}{l}\text { Logaritmo natural do tempo de constituição } \\
\text { da entidade até 2015 (em anos). }\end{array}$ & IDADE & Independente \\
\hline Auditoria externa & $\begin{array}{l}\text { Presença de parecer ou relatório de auditoria externa } \\
\text { (dummies). }\end{array}$ & AUD & Independente \\
\hline $\begin{array}{l}\text { Subvenções } \\
\text { governamentais }\end{array}$ & $\begin{array}{l}\text { Obtenção de subvenções governamentais em 2015 } \\
\text { (dummies). }\end{array}$ & SUB & Independente \\
\hline
\end{tabular}

Fonte: Autores 
Para análise dos dados, foi identificado o nível de conformidade (NC) das organizações às normas contábeis vigentes. Para isso, os dados foram tabulados e examinados com base em um check-list, desenvolvido a partir da ITG 2002 (R1) (CFC, 2012; CFC, 2015), composto por 41 itens de verificação que englobam: (i) Reconhecimento (com 12 itens), (ii) Demonstrações Contábeis (com 11 itens), e (iii) Notas Explicativas (com 18 itens). O nível de conformidade (que variou de 0 a $100 \%$ ) foi obtido ao calcular a proporção dos itens atendidos em relação ao total aplicável de itens apresentados no check-list, tendo em vista que todos os 41 itens possuem o mesmo peso.

Por fim, o nível de conformidade identificado foi correlacionado, através da técnica de correlação de Pearson e regressão linear múltipla, com algumas características organizacionais das fundações, selecionadas para esta pesquisa, sendo elas: porte, tempo de constituição, auditoria externa e subvenções governamentais, de modo a se identificar as possíveis causas do nível de conformidade dessas instituições às normas de contabilidade em vigor. Para isso, foram testados e comprovados os pressupostos de regressão.

Deste modo, as hipóteses estatísticas a serem testadas são:

H1 - O nível de conformidade está relacionado positivamente ao porte das fundações privadas brasileiras.

H2 - O nível de conformidade está relacionado positivamente ao tempo de constituição das fundações privadas brasileiras.

H3 - O nível de conformidade está relacionado positivamente à presença de auditoria externa nas fundações privadas brasileiras.

H4 - O nível de conformidade está relacionado positivamente à obtenção de subvenções governamentais das fundações privadas brasileiras.

Assim sendo, foi elaborado o modelo e gerada a seguinte equação de regressão:

$$
N C=\beta_{0}+\beta_{1} P O R T E+\beta_{2} I D A D E+\beta_{3} A U D+\beta_{4} S U B+\varepsilon
$$

Em que:

NC, PORTE, IDADE, AUD e SUB são, respectivamente, o nível de conformidade, o porte, o tempo de constituição, a auditoria externa e as subvenções governamentais.

\section{Apresentação dos Resultados}

\section{Identificação do nível de conformidade}

De forma geral, foi possível verificar que nas demonstrações contábeis do exercício findo em 2015, o nível de conformidade geral às normas de contabilidade vigentes, representadas pela ITG 2002 (R1) (CONSELHO FEDERAL DE CONTABILIDADE， 2012; CONSELHO FEDERAL DE CONTABILIDADE, 2015), foi de $64,53 \%$. Este resultado reflete que os relatórios contábeis examinados não atendem a todos os requisitos exigidos pelas normas em vigor, mas é um indicador melhor do que o encontrado no estudo de Ramos e Klann (2015), cuja média de evidenciação foi de $32,4 \%$, ressalvando-se que a base de dados, a composição dos índices utilizados e a população pesquisada diferem deste estudo.

$\mathrm{Na}$ Tabela 1, apresentam-se as estatísticas descritivas do nível de conformidade das demonstrações contábeis das entidades analisadas.

Tabela 1 - Estatística descritiva do nível de conformidade.

\begin{tabular}{cccccc}
\hline & Média & Mediana & Menor & Maior & Desvio padrão \\
\hline Nível de conformidade & $64,53 \%$ & $74,19 \%$ & $3,13 \%$ & $100,00 \%$ & $25,23 \%$ \\
\hline
\end{tabular}

Fonte: Autores 
Ao verificar o nível de conformidade identificado, observa-se que o maior índice encontrado foi de $100 \%$, o que representa uma evidenciação satisfatória, divergindo completamente do menor índice, que foi de 3,13\%, um nível preocupante, porém um caso isolado. Para maior clareza, serão apresentados os resultados obtidos para cada seção do check-list.

A seção denominada “(i) Reconhecimento”, que mais se relaciona com a contabilização característica do Terceiro Setor, expressou uma evidenciação de 65,49\%. No Quadro 2, estão listados os itens apurados com os respectivos níveis de conformidade.

Quadro 2 - Reconhecimento.

\begin{tabular}{|c|l|c|c|c|}
\hline \multicolumn{1}{|c|}{ Reconhecimento } & \multicolumn{3}{|c|}{2015} \\
\cline { 3 - 5 } \multicolumn{1}{|c|}{ Total } & n & T. A. & \% \\
\hline 1 & $\begin{array}{l}\text { As receitas e despesas são reconhecidas, mensalmente, respeitando o princípio da } \\
\text { competência? }\end{array}$ & 362 & 384 & $94,27 \%$ \\
\hline 2 & $\begin{array}{l}\text { As doações e subvenções recebidas para custeio e investimento foram reconhecidas } \\
\text { como receita no resultado? }\end{array}$ & 274 & 334 & $82,04 \%$ \\
\hline 3 & Os registros contábeis estão de forma segregada, identificáveis por tipo de atividade? & 40 & 119 & $33,61 \%$ \\
\hline 4 & $\begin{array}{l}\text { A contrapartida das contas de subvenção, contribuição para custeio e investimento, bem } \\
\text { como da isenção e do incentivo fiscal registrados no ativo, estão em conta especifica do } \\
\text { passivo? }\end{array}$ & 185 & 363 & $50,96 \%$ \\
\hline 5 & As receitas vinculadas à aplicação especifica estão registradas em contas próprias? & 240 & 279 & $86,02 \%$ \\
\hline 6 & Os benefícios concedidos a título de gratuidade estão reconhecidos de forma segregada? & 150 & 241 & $62,24 \%$ \\
\hline 7 & A entidade possui provisão para cobrir as perdas esperadas sobre créditos a receber? & 179 & 347 & $51,59 \%$ \\
\hline 8 & O valor do superávit ou déficit está incorporado ao Patrimônio Social? & 299 & 384 & $77,86 \%$ \\
\hline 9 & $\begin{array}{l}\text { O benefício concedido como gratuidade por meio da prestação de serviços é reconhecido } \\
\text { como se efetivamente praticado? }\end{array}$ & 139 & 241 & $57,68 \%$ \\
\hline 10 & $\begin{array}{l}\text { Os registros contábeis estão segregados de forma que permitam a apuração das } \\
\text { informações para prestação de contas exigidas? }\end{array}$ & 254 & 384 & $66,15 \%$ \\
\hline 11 & O trabalho voluntário está reconhecido como se tivesse ocorrido o desembolso financeiro? & 54 & 64 & $84,38 \%$ \\
\hline 12 & A renúncia fiscal relacionada à atividade está evidenciada nas demonstrações contábeis? & 97 & 331 & $29,31 \%$ \\
\hline
\end{tabular}

Legenda: T. A.: total aplicável.

Fonte: Conselho Federal de Contabilidade (2015) e Ramos e Klann (2015)

A seção “(ii) Demonstrações Contábeis” trata da elaboração dos relatórios contábeis exigidos, de alterações das nomenclaturas de algumas contas do patrimônio social, das evidenciações das gratuidades concedidas e serviços voluntários obtidos, dentre outras. Foi obtido um nível de evidenciação de 77,94\%, conforme demonstrado no Quadro 3.

Quadro 3 - Demonstrações Contábeis.

\begin{tabular}{|c|l|c|c|c|}
\hline \multicolumn{2}{|c|}{ Demonstrações Contábeis } & \multicolumn{3}{c|}{2015} \\
\cline { 3 - 5 } \multicolumn{2}{|c|}{} & n & T. A. & \% \\
\hline & Total & $\mathbf{2 8 7 2}$ & $\mathbf{3 6 8 5}$ & $\mathbf{7 7 , 9 4 \%}$ \\
\hline 13 & A entidade elabora e divulga o Balanço Patrimonial? & 384 & 384 & $100,00 \%$ \\
\hline 14 & A entidade elabora e divulga a Demonstração do Resultado? & 367 & 384 & $95,57 \%$ \\
\hline
\end{tabular}

Continua 


\section{Continuação}

\begin{tabular}{|c|l|c|c|c|}
\hline 15 & A entidade elabora e divulga a Demonstração das Mutações do Patrimônio Líquido? & 299 & 384 & $77,86 \%$ \\
\hline 16 & A entidade elabora e divulga a Demonstração dos Fluxos de Caixa? & 286 & 384 & $74,48 \%$ \\
\hline 17 & $\begin{array}{l}\text { Na Demonstração de Resultado, as receitas são subdivididas em receitas com e sem } \\
\text { restrições? }\end{array}$ & 219 & 380 & $57,63 \%$ \\
\hline 18 & $\begin{array}{l}\text { No Balanço Patrimonial, a denominação da conta Capital foi substituída por Patrimônio } \\
\text { Social? }\end{array}$ & 316 & 384 & $82,29 \%$ \\
\hline 19 & $\begin{array}{l}\text { No Balanço Patrimonial, a denominação da conta Lucros ou Prejuízos Acumulados foi } \\
\text { substituída por Superávit ou Déficit? }\end{array}$ & 329 & 384 & $85,68 \%$ \\
\hline 20 & $\begin{array}{l}\text { Na Demonstração de Resultado, das Mutações do Patrimônio Líquido e dos Fluxos } \\
\text { de Caixa, as palavras lucro ou prejuízo foram substituídas por superávit ou déficit do } \\
\text { período? }\end{array}$ & 320 & 384 & $83,33 \%$ \\
\hline 21 & $\begin{array}{l}\text { Foram destacadas, na Demonstração de Resultado, as informações de gratuidade } \\
\text { concedidas? }\end{array}$ & 185 & 245 & $75,51 \%$ \\
\hline 22 & $\begin{array}{l}\text { Foram destacadas, na Demonstração de Resultado, as informações de serviços voluntários } \\
\text { bbtidos? }\end{array}$ & 54 & 68 & $79,41 \%$ \\
\hline 23 & $\begin{array}{l}\text { As doações dos associados foram classificadas nos fluxos de atividades operacionais? } \\
\text { (DFC) }\end{array}$ & 113 & 304 & $37,17 \%$ \\
\hline
\end{tabular}

Legenda: T. A.: total aplicável.

Fonte: Conselho Federal de Contabilidade (2015) e Ramos e Klann (2015)

A terceira e última seção, "(iii) Divulgação", Constatou-se ainda, que essas fundações lista os fatos que devem ser divulgados em apresentaram um nível de conformidade de 55\%, Notas Explicativas. Verificou-se que $83,33 \%$ portanto, as informações contidas não cumprem das entidades elaboraram suas demonstrações na totalidade as normas vigentes de contabilidade, contábeis acompanhadas de Notas Explicativas. como detalhado no Quadro 4.

Quadro 4 - Divulgação.

\begin{tabular}{|c|c|c|c|c|}
\hline & \multirow{2}{*}{ Divulgação } & \multicolumn{3}{|c|}{2015} \\
\hline & & \multirow{2}{*}{$\frac{\mathrm{n}}{3046}$} & \multirow{2}{*}{ T. A. } & \multirow{2}{*}{$\frac{\%}{55,00 \%}$} \\
\hline & Total & & & \\
\hline 24 & As Demonstrações Contábeis são acompanhadas das Notas Explicativas? & 320 & 384 & $83,33 \%$ \\
\hline 25 & $\begin{array}{l}\text { As NE apresentam o contexto operacional da entidade (natureza social e econômica e os } \\
\text { objetivos sociais)? }\end{array}$ & 303 & 384 & $78,91 \%$ \\
\hline 26 & $\begin{array}{l}\text { As NE apresentam os critérios de apuração da receita e da despesa de gratuidade, doação, } \\
\text { subvenção, contribuição e aplicação de recursos? }\end{array}$ & 278 & 380 & $73,16 \%$ \\
\hline 27 & As NE evidenciam a relação dos tributos objeto de renúncia fiscal? & 227 & 384 & $59,11 \%$ \\
\hline 28 & As NE apresentam as subvenções recebidas? & 194 & 334 & $58,08 \%$ \\
\hline 29 & As NE apresentam a aplicação das subvenções recebidas? & 185 & 334 & $55,39 \%$ \\
\hline 30 & As NE apresentam as responsabilidades decorrentes de subvenções? & 126 & 334 & $37,72 \%$ \\
\hline 31 & As NE evidenciam os recursos de aplicação restrita? & 215 & 317 & $67,82 \%$ \\
\hline 32 & As NE descrevem as responsabilidades decorrentes dos recursos de aplicação restrita? & 181 & 317 & $57,10 \%$ \\
\hline 33 & As NE apresentam os recursos sujeitos a restrição ou vinculação por parte do doador? & 185 & 334 & $55,39 \%$ \\
\hline 34 & As NE apresentam as taxas de juros das obrigações a longo prazo? & 46 & 224 & $20,54 \%$ \\
\hline 35 & As NE apresentam as datas de vencimento das obrigações a longo prazo? & 46 & 224 & $20,54 \%$ \\
\hline
\end{tabular}




\begin{tabular}{|c|l|c|c|c|}
\hline 36 & As NE apresentam garantias das obrigações a longo prazo? & 33 & 224 & $14,73 \%$ \\
\hline 37 & As NE apresentam informações sobre os seguros contratados? & 135 & 266 & $50,75 \%$ \\
\hline 38 & $\begin{array}{l}\text { As NE apresentam os critérios e procedimentos do registro contábil de depreciação, } \\
\text { amortização e exaustão do ativo imobilizado? }\end{array}$ & 244 & 384 & $63,54 \%$ \\
\hline 39 & $\begin{array}{l}\text { As NE apresentam a segregação dos atendimentos com recursos próprios dos demais } \\
\text { atendimentos realizados pela entidade? }\end{array}$ & 126 & 300 & $42,00 \%$ \\
\hline 40 & As NE apresentam as gratuidades praticadas registradas de forma segregada? & 156 & 283 & $55,12 \%$ \\
\hline 41 & $\begin{array}{l}\text { Foram divulgadas em NE por tipo de atividade, as informações de serviços voluntários } \\
\text { obtidos? }\end{array}$ & 46 & 131 & $35,11 \%$ \\
\hline
\end{tabular}

Legenda: T. A.: total aplicável.

Fonte: Conselho Federal de Contabilidade (2015) e Ramos e Klann (2015)

Pode-se observar que a seção "(iii) Caracterização das entidades do Terceiro Divulgação" é a que tem o menor nível Setor pesquisadas de conformidade, sendo 55\%. Esta baixa evidenciação é preocupante, já que as notas explicativas são importantes para a compreensão das informações acerca dos demonstrativos contábeis, pois, além de adicionar ou detalhar os dados quantitativos, a entidade poderá apresentar dados qualitativos que poderão esclarecer questões em relação às informações fornecidas nas demais demonstrações.

Conforme já mencionado, as organizações do Terceiro Setor analisadas nessa pesquisa estão enquadradas como fundação privada. Para melhor entendimento, será apresentada a estatística descritiva das características organizacionais destas entidades. A Tabela 2 apresenta o porte das fundações privadas estudadas, o qual foi classificado pelo total do ativo das entidades, bem como a idade dessas organizações.

Tabela 2 - Estatística descritiva do tamanho e tempo de constituição das fundações privadas.

\begin{tabular}{lccccc}
\hline & Média & Mediana & Menor & Maior & Desvio padrão \\
\hline Ativo total & 179.419 .800 & 16.406 .096 & 921 & 5.943 .919 .000 & $666.942 .606,78$ \\
Idade & 27 & 26 & 2 & 95 & 19,26 \\
\hline
\end{tabular}

Fonte: Autores

Observa-se, através da Tabela 2, que a entidade com maior patrimônio constitui-se de um ativo total de $\mathrm{R} \$ 5.943 .919 .000,00$, enquanto que o ativo total médio das entidades é de $\mathrm{R} \$ 179.419 .800,70$.

Além do porte, o tempo de constituição das entidades ou idade também está relacionado à qualidade de evidenciação, já que, ao passar do tempo, as organizações adquirem mais experiência e práticas nos procedimentos internos existentes. O tempo de constituição médio das entidades é de 27 anos, enquanto que a mais antiga e a mais nova possuem 95 e 2 anos, respectivamente.

Dentre as entidades analisadas, 67,27\% informaram que possuem parecer de auditoria externa nas suas demonstrações contábeis. Ainda é possível identificar que 73,25\% recebem auxílio governamental através de subvenções. 
Relação entre o nível de conformidade das demonstrações contábeis e as características organizacionais das fundações

O objetivo principal desse estudo é avaliar a relação entre as características organizacionais e o nível de conformidade das demonstrações contábeis das fundações privadas brasileiras. Deste modo, inicialmente, foi realizado o teste de correlação de Pearson para analisar a relação entre as variáveis: porte (PORTE) e tempo de constituição (IDADE) com o nível de conformidade encontrado nas fundações estudadas. Os resultados do mencionado teste são apresentados na Tabela 3.

Tabela 3 - Teste de correlação de Pearson.

\begin{tabular}{ccccc}
\hline & & $N C$ & PORTE & IDADE \\
\hline \multirow{2}{*}{ NC } & Correlação & 1 & 0,428 & $-0,082$ \\
& $p$-valor & 1 & 0,000 & 0,108 \\
\multirow{3}{*}{ PORTE } & Correlação & & 1 & 0,277 \\
& $p$-valor & & 1 & 0,000 \\
\multirow{2}{*}{ IDADE } & Correlação & & & 1 \\
& $p$-valor & & & 1 \\
\hline
\end{tabular}

Nota: a correlação é significativa no nível 0,05. Legenda: NC: nível de conformidade; PORTE: $\log$ do porte; IDADE: $\log$ do tempo de constituição.

Fonte: Autores

O resultado do teste de correlação (vide Tabela 3) apresenta uma relação positiva e significativa $(\mathrm{p}<0,05)$ entre o nível de conformidade (NC) e porte. Já a correlação entre o NC e o tempo de constituição (idade) não foi significativa, entretanto observa-se uma associação negativa entre essas variáveis.

Após a realização do teste de correlação, foram realizados e comprovados os testes de pressupostos da regressão, o que tornou o modelo aceitável. Na Tabela 4 são apresentados os resultados da regressão linear múltipla.

Tabela 4 - Regressão linear múltipla.

\begin{tabular}{|c|c|c|c|c|}
\hline \multicolumn{2}{|c|}{ Estatística de regressão } & & & \\
\hline $\mathrm{R}$ múltiplo & 0,645 & & & \\
\hline R-quadrado & 0,415 & & & \\
\hline R-quadrado ajustado & 0,409 & & & \\
\hline F de significação & 0,000 & & & \\
\hline Observações & 384 & & & \\
\hline Variáveis & Coeficientes & Stat $t$ & valor-P & $V I F$ \\
\hline Interseção & 0,145 & 1,8305 & 0,068 & \\
\hline SUB & 0,043 & 1,8940 & 0,059 & 1,050 \\
\hline AUD & 0,257 & 10,3895 & 0,000 & 1,376 \\
\hline PORTE & 0,062 & 5,1462 & 0,000 & 1,463 \\
\hline IDADE & $-0,118$ & $-4,5377$ & 0,000 & 1,117 \\
\hline
\end{tabular}

Legenda: NC: nível de conformidade; PORTE: log do porte; IDADE: log do tempo de constituição; AUD: auditoria externa presente; SUB: recebe subvenções.

Fonte: Autores 
A partir da Tabela 4 é possível apontar que o modelo proposto é significativo e as variáveis independentes conseguem explicar 40,9\% do nível de conformidade das demonstrações contábeis, sendo que as variáveis AUD e PORTE apresentaram relacionamento positivo com o nível de conformidade (NC). A variável SUB não se mostrou significativa $(\mathrm{p}>0,05)$ no modelo, enquanto a variável IDADE mostrou-se significativa $(\mathrm{p}<0,05)$, o que diverge do teste de correlação de Pearson.

Em relação à variável SUB, apesar de próximo do nível de significância adotado $(0,05)$, não apresentou significância. A não existência de relacionamento significativo entre a obtenção de subvenções governamentais e o nível de conformidade é oposto ao previsto, já que é desejável que as organizações que recebem recursos públicos prestem contas a sociedade com maior qualidade.

Já as variáveis AUD e PORTE demonstram associação positiva e significativa $(p<0,01)$ no contexto analisado (Tabela 4), o mesmo observado no teste de correlação de Pearson para a variável porte (Tabela 3). Os resultados satisfazem a expectativa que empresas maiores e com auditoria externa possuem melhores controles informacionais, o que é necessário para uma boa tomada de decisão, convergindo para uma estrutura sistemática apropriada para prestação de contas com mais qualidade e transparentes.

Com relação ao porte, esse resultado converge com o encontrado na pesquisa de Ramos e Klann (2015) que também identificaram relação positiva entre o tamanho e a qualidade da informação contábil, no entanto, diverge quanto a variável auditoria externa, pois o estudo anterior (2015) rejeitou a hipótese de associação positiva entre a presença de auditoria e o índice de qualidade da informação contábil (IQIC). Nesse sentido, Ramos e Klann (2015, p. 13) relataram que a influência da auditoria externa sobre o IQIC não era conclusiva, abrindo espaço para que novas pesquisas fossem realizadas no âmbito do Terceiro Setor.
A variável IDADE apresentou relacionamento negativo no modelo proposto, com $\mathrm{p}<0,05$. Essa associação é contrária às expectativas deste estudo, uma vez que a experiência das organizações, ao passar do tempo, tende a melhores demonstrações contábeis, o que sugere que as instituições do Terceiro Setor mais jovens estão sendo mais propensas a divulgar suas prestações de contas com qualidade, diferentemente das entidades mais antigas. No entanto, esse achado difere do estudo de Ramos e Klann (2015) que identificou relacionamento positivo entre o tempo de constituição e a qualidade da informação contábil.

Frente a esses resultados, é possível aceitar a H1 da pesquisa, a qual presumia relação positiva entre o porte das fundações privadas e o nível de conformidade das demonstrações financeiras.

A H2, que supunha a presença de relação positiva entre o nível de evidenciação das demonstrações contábeis e a tempo de constituição (idade) das organizações sem fins lucrativos pesquisadas, não pode ser aceita, pois tanto o teste de regressão quanto o teste de correlação evidenciam, mutuamente, uma associação negativa entre o NC calculado e o tempo de constituição das fundações privadas analisadas.

A H3, que preconizava uma relação positiva entre as entidades do Terceiro Setor que possuem auditoria externa e o nível de conformidade das normas contábeis em seus demonstrativos, pode ser aceita, pois a regressão linear demonstrou relacionamento significativo.

Já a H4, que previa um relacionamento positivo entre as fundações privadas que possuem subvenções governamentais e o nível de conformidade das demonstrações contábeis, não pode ser aceita ao nível de significância adotado de 5\%. Apesar de se esperar uma melhor conformidade das demonstrações contábeis das entidades que recebem recursos governamentais, o teste de regressão não apontou associação significativa entre essas variáveis. Diante disso, esse resultado não pode ser considerado conclusivo e diverge do estudo de Lima e Pereira (2011) que 
identificou relação significativa positiva entre os índices de disclosure analisados e as subvenções no contexto das Instituições de Ensino Superior Filantrópicas do Brasil.

\section{Conclusão}

Esse estudo teve como objetivo verificar a relação entre a divulgação de informações contábeis nos padrões especificados pelas normas vigentes e as características organizacionais das fundações privadas brasileiras. Para tal, realizouse uma pesquisa documental com 384 fundações privadas brasileiras.

No âmbito dessas entidades, os resultados indicaram um nível de conformidade (NC) geral às normas de contabilidade em vigor de $64,53 \%$. Esse indicador foi analisado por seções, a saber: (i) Reconhecimento, o NC foi de $65,49 \%$, o que demonstra que as normas que mais se relacionam à contabilização característica do Terceiro Setor não estão sendo atendidas em sua totalidade; (ii) Demonstrações Contábeis, o NC foi de 77,94\% e, embora seja o melhor resultado das três seções do check-list, ainda não é satisfatório, já que se esperava um nível de conformidade próximo a 100\%; e (iii) Divulgação, apesar de 83,33\% das organizações divulgarem as Notas Explicativas, o NC foi de apenas 55\%, revelando um índice insatisfatório de conformidade das Notas Explicativas.

Pode-se notar um aumento no nível de conformidade em relação ao estudo de Ramos e Klann (2015) que identificou um índice médio da qualidade da informação contábil de 32,4\%, entretanto, essa comparação deve considerar diferenças essencialmente quanto à base de dados utilizada, à população de estudo e à composição dos indicadores utilizados. Ainda assim, percebeuse que as fundações privadas ainda não estão atendendo a todos os requisitos recomendados pelas normas brasileiras vigentes; sendo necessária a evolução no processo de prestação de contas das informações contábeis e da fiscalização por parte dos órgãos reguladores.
No que se refere à análise da relação entre as características organizacionais das fundações e o nível de conformidade às normas vigentes, os resultados constatados no modelo de regressão indicaram relacionamento significativo e positivo das variáveis porte e presença de auditoria com a evidenciação contábil divulgada, enquanto o tempo de constituição apresentou associação negativa. Conclui-se, portanto, que organizações maiores tendem apresentar maior conformidade às normas, o que pode ser explicado pelos custos da evidenciação e de auditoria serem absorvidos mais facilmente e, possivelmente, pela existência de melhores controles internos e mais profissionais conhecedores das normas de contabilidade em vigor.

Para pesquisas futuras, sugere-se a continuidade deste estudo, porém com as entidades do Terceiro Setor em qualquer forma legal (fundações, associações, entre outras), e também a inclusão de outras características que venham afetar o nível de conformidade das demonstrações contábeis com as normas brasileiras de contabilidade.

\section{Referências}

ASSIS, M. S.; MELLO, G. R.; SLOMSKI, V. Transparência nas entidades do terceiro setor: a demonstração do resultado econômico como instrumento de mensuração de desempenho. In: CONGRESSO USP DE CONTABILIDADE E CONTROLADORIA, 6., 2006, São Paulo. Anais [...]. São Paulo: USP, 2006. Disponível em: https:// bit.ly/2W82AYT. Acesso em: 15 fev. 2020.

BRASIL. Lei $n^{\circ}$ 10.406, de 10 de janeiro de 2002. Institui o Código Civil. Brasília: Presidência da República, 2002. Disponível em: https://bit. ly/2BIqF1f. Acesso em: 15 fev. 2020.

BRASIL. Ministério da Justiça. Manual CNEs/ $M J$ : cadastro nacional de entidades qualificadas pelo Ministério da Justiça. Brasília: Ministério da Justiça, 2007. Disponível em: https://bit. ly/3gusZYq. Acesso em: 15 fev. 2020. 
BUSHMAN, R. M.; PIOTROSKI, J. D.; SMITH, A. J. What determine corporate transparency? Journal of Accounting Research, Chicago, v. 42, n. 2, p. 207-252, may. 2004. Doi: https://doi. org/10.1111/j.1475-679X.2004.00136.x

CARNEIRO, A. de F.; OLIVEIRA, D. de L.; TORRES, L. C. Accountability e prestação de contas das organizações do terceiro setor: uma abordagem à relevância da contabilidade. Sociedade, Contabilidade e Gestão, Rio de Janeiro, v. 6, n. 2, jul. /dez. 2011. Disponível em: https://bit. 1y/31TBHvd. Acesso em: 19 jan. 2020.

COLAUTO, R. D.; BEUREN, I. M. Coleta, análise e interpretação dos dados. In: BEUREN, I. M. (org.). Como elaborar trabalhos monográficos em contabilidade: teoria e prática. 3. ed. São Paulo: Atlas, 2014. p. 117-144.

CONSELHO FEDERAL DE CONTABILIDADECFC. Norma Brasileira de Contabilidade ITG 2002 (R1), de 21 de agosto de 2015. Altera a ITG 2002 que trata de entidades sem finalidade de lucros. Diário Oficial da União, Brasília, 2 set. 2015. Disponível em: https://bit.ly/2XVPcrG. Acesso em: 15 fev. 2020.

CONSELHO FEDERAL DE CONTABILIDADECFC. Resolução CFC 1.055, de 24 de outubro de 2005. Cria o Comitê de Pronunciamentos Contábeis (CPC). Brasília: CFC, 2005. Disponível em: https://bit.ly/3gBb3v5. Acesso em: 15 fev. 2020 .

CONSELHO FEDERAL DE CONTABILIDADECFC. Resolução CFC 1.409, de 21 de setembro de 2012. Aprova a ITG 2002: entidade sem finalidade de lucros. Brasília: CFC, 2012. Disponível em: https://bit.ly/38xKHaT. Acesso em: 15 fev. 2020.

CRUZ, C. V. O. A relevância da informação contábil para os investidores sociais privados de entidades do terceiro setor no Brasil: uma investigação empírica. 2010. 165 f. Tese (Doutorado em Controladoria e Contabilidade) - Faculdade de Economia, Administração e Contabilidade, Universidade de São Paulo, São Paulo, 2010. Disponível em: https://bit.ly/2D7QVlU. Acesso em: 24 mar. 2020.
CUNHA, J. H. da C.; MATIAS-PEREIRA, J. Captação de recursos no terceiro setor: fatores estratégicos para divulgação de informações. Revista Contemporânea de Contabilidade, Florianópolis, v. 9, n. 18, 2012. Doi: https:// doi.org/10.5007/2175-8069.2012v9n18p83. Disponível em: https://bit.ly/2Z2nsCn. Acesso em: 24 mar. 2020.

CUNHA, P. R.; KLANN, R. C.; RANGEL, S.; SCARPIN, J. E. Procedimentos de auditoria aplicados pelas empresas de auditoria independente de Santa Catarina em entidades do terceiro setor. Revista de Contabilidade e Organizações, Ribeirão Preto, v. 4, n. 10, 2010. Doi: https://doi. org/10.11606/rco.v4i10.34777. Disponível em: https://bit.ly/2VPYAvV. Acesso em: 24 mar. 2020.

FISCHER, R. M. O desafio da colaboração: práticas de responsabilidade social entre empresa e terceiro setor. São Paulo: Gente, 2002.

FRANÇA, J. A. de (Coord.). Manual de procedimentos para o terceiro setor: aspectos de gestão e de contabilidade para entidades de interesse social. Brasília: CFC: FBC, 2015. Disponível em: https://bit.ly/2O26VIk. Acesso em: 25 jul. 2016.

GIL, A. C. Como elaborar projetos de pesquisa. 4. ed. São Paulo: Atlas, 2008.

HERCULANO, H.A.; MOURA, G. D. Informação contábil e concentração acionária: Análise sob a ótica da persistência e da oportunidade. Revista Ambiente Contábil, Natal, v. 7, n. 2, 2015. Disponível em: https://bit.ly/2BIxsIf. Acesso em: 24 mar. 2020.

HOLTHAUSEN, R. W. Accounting standards, financial reporting outcomes. Journal of Accounting Research, Chicago, v. 47, May 2009. Doi: https:// doi.org/10.1111/j.1475-679X.2009.00330.x

IASB - INTERNATIONAL ACCOUNTING STANDARDS BOARD. Normas internacionais de contabilidade 2001. São Paulo: IBRACON, 2002.

IBGE. As fundações privadas e associações sem fins lucrativos no Brasil. 2010. Disponível em: https://bit.ly/2CdOApm. Acesso em: 13 out. 2016. 
JEGERS, M. Managerial economics of nonprofit organizations. Londres: Routledge, 2008. Disponível em: https://bit.ly/2Z4uKpt. Acesso em: 5 jan. 2016.

LIMA, E. M.; PEREIRA, C. A. Associação entre índices de disclosure e características corporativas das Instituições de Ensino Superior Filantrópicas do Brasil - IESFB. Revista de Contabilidade e Organizações, Ribeirão Preto, v. 5, n. 11, 2011. Doi: https://doi.org/10.11606/rco.v5i11.34784. Disponível em: https://bit.ly/2ZMpjue. Acesso em: 5 jan. 2020.

MARTINS, G. de A.; THEÓPHILO, C. R. Metodologia da investigação científica para ciências sociais aplicadas. 2. ed. São Paulo: Atlas, 2009.

MURCIA, F. D. R.; SANTOS, A. Discretionarybased disclosure: evidence from the Brazilian market. BAR: Brazilian Administration Review, Rio de Janeiro, v. 9, n. 1, p. 88-109, Jan. / Mar. 2012. Doi: https://doi.org/10.1590/S180776922012000100006. Disponível em: https://bit. ly/2Ay0lWX. Acesso em: 24 mar. 2020.

MURCIA, F. D. R.; SANTOS, A. Fatores determinantes do nível de disclosure voluntário de companhias abertas no Brasil. Revista de Educação e Pesquisa em Contabilidade (REPeC), Brasília, v. 3, n. 2, 2009. Doi: https://doi.org/10.17524/repec. v3i2.68. Disponível em: https://bit.ly/2CdOYnO. Acesso em: 24 mar. 2020.

NIYAMA, J. K.; GOMES, A. L. O. Contribuição ao aperfeiçoamento dos procedimentos de evidenciação contábil aplicáveis às demonstrações financeiras de bancos e instituições assemelhadas. In: CONGRESSO BRASILEIRO DE CONTABILIDADE, 15., 1996, Fortaleza, CE. Anais [...]. Fortaleza: Centro de Convenções, 1996. CD-ROM. Tema: Contabilidade: Responsabilidade e Compromisso Social.

OLAK, P. A.; NASCIMENTO, D. T. de. Contabilidade para entidades sem fins lucrativos (terceiro setor). 2. ed. São Paulo: Altlas, 2008.

PACHECO, R. R.; MACAGNAN, C. B.; SEIBERT, R. M. Fatores explicativos do nível de evidenciação de informações de organizações do terceiro setor. Revista de Gestão, Finanças e Contabilidade, Salvador, v. 6, n. 2, p. 72-93, maio/ago. 2016. Doi: http://dx.doi.org/10.18028/rgfc.v6i2.1764
RAMOS, F. M.; KLANN, R. C. Relação entre Qualidade da Informação Contábil e as Características Organizacionais das Entidades do Terceiro Setor. In: CONGRESSO USP DE CONTROLADORIA E CONTABILIDADE, 15., 2015, São Paulo, SP. Anais [...]. São Paulo: USP, 2015. Disponível em: https://bit.ly/3grVSEs. Acesso em: 28 mar. 2020.

ROSSI JUNIOR, L. R. A gestão para resultados como ferramenta administrativa nas organizações do terceiro setor. 1998. 73 f. Dissertação (Mestrado em Administração) - Escola de Administração de São Paulo, Fundação Getúlio Vargas, São Paulo, 1998. Disponível em: https://bit.ly/2DiYarz. Acesso em: 28 mar. 2020.

SILVEIRA, D. da; BORBA, J. A. Evidenciação contábil de fundações privadas de educação e pesquisa: uma análise da conformidade das demonstrações contábeis de entidades de Santa Catarina. Revista Contabilidade Vista \& Revista, Belo Horizonte, v. 21, n. 1, p. 41-68, jan. /mar. 2010. Disponível em: https://bit.ly/2NZyWAn. Acesso em: 13 jan. 2020.

TRUSSEL, J. M.; PARSONS, L. M. Finances reporting factors affecting donations to charitable not-for-profit organizations. Advances in Accounting, Oxford, v. 23, 2007. Doi: https:// dx.doi.org/10.2139/ssrn.481383. Disponível em: https://bit.ly/2Z1AH6v. Accesso em: 5 jan. 2020.

UYAR, A.; KILIC, M.; BAYYURT, B. Association between firm characteristics and corporate voluntary disclosure: evidence from Turkish listed companies. Intangible Capital, Barcelona, v. 9, n. 4, 2013. Doi: http://dx.doi.org/10.3926/ic.439 Disponível em: https://bit.ly/3eb6kPu. Acesso em: 19 jan. 2016. 